\title{
Systemic isotretinoin treatment in a renal transplant patient developing sebaceous hyperplasia due to cyclosporine
}

\author{
(D) Ceyda Caytemel, ${ }^{1}$ (i) Filiz Topaloglu Demir, ${ }^{1}$ (i) Esen Gul Uzuner, ${ }^{2}$ (i) Zafer Turkoglu ${ }^{1}$ \\ ${ }^{1}$ Department of Dermatology, Haseki Training and Research Hospital, Istanbul, Turkey \\ 2Department of Pathology, Haseki Training and Research Hospital, Istanbul, Turkey
}

\begin{abstract}
Sebaceous hyperplasia (SH) is a benign tumor with telangiectasia on it, yellowish or skin-colored, with papulosis. Besides genetic factors, aging, ultraviolet rays, sex hormones, calcineurin inhibitors, such as cyclosporin, tacrolimus and systemic steroids, play a role in the development of sebaceous hyperplasia. Cyclosporin is widely used in organ transplant patients. Acne, keratosis pilaris, sebaceous hyperplasia and epidermoid cysts, which are rare side effects, are frequently seen in renal transplant patients and it is suggested that the pilosebaceous unit develops as a result of occlusion with keratinous material. It is thought that cyclosporine causes these side effects by increasing the secretion of sebum and 5-alpha reductase enzyme activity. In this case study, wepresent here a 36-year-old female patient who had been on cyclosporine treatment for 25 years and had a large number of yellowish, umblike papules on her face for 20 years. She had been diagnosed with cyclosporin triggered by clinical and histopathological findings. The patient was started on $40 \mathrm{mg} /$ day $(0.6 \mathrm{mg} / \mathrm{kg} /$ day $)$ systemic isotretinoin treatment, and after two months treatment, the patient had almost complete regression of the lesions. Systemic isotretinoin is effective and easy to treat treatment for patients with multiple lesions, especially when compared to other treatments. In addition, all of the cases reported in the literature are male, and this report presents the first female transplant patient with $\mathrm{SH}$, which is induced by cyclosporine use.
\end{abstract}

Keywords: Cyclosporine; renal transplant; sebaceous hyperplasia; systemic isotretinoin.

Cite this article as: Caytemel C, Topaloglu Demir F, Uzuner EG, Turkoglu Z. Systemic isotretinoin treatment in a renal transplant patient developing sebaceous hyperplasia due to cyclosporine. North Clin Istanb 2020;7(6):628-630.

$\mathrm{S}^{\mathrm{s}}$ ebaceous hyperplasia $(\mathrm{SH})$ is a benign sebaceous gland hyperproliferation that is seen in advanced ages with the effects of intrinsic aging, ultraviolet rays and genetic predisposition. It may be familial or as a component of diseases, such as Muir-Torre syndrome [1]. It is rarely reported as a cutaneous side effect associated with cyclosporine use in transplant patients. Systemic isotretinoin appears to be an effective treatment option in a short time and with a low dose in a few transplant patients in the literature in the treatment of $\mathrm{SH}[2]$. We present a female case that had been treated with cyclosporine for 25 years and had a complete response to isotretinoin treatment.

\section{CASE REPORT}

A 32-year-old female patient presented to our clinic with many small bulging lesions on her face. In 1990, she underwent bilateral nephrectomy due to chronic pyelonephritis and renal transplantation from her mother in $1993.75 \mathrm{mg} /$ day $(1.25 \mathrm{mg} / \mathrm{kg} /$ day $)$ cyclosporine, $75 \mathrm{mg} /$ day $(1.25 \mathrm{mg} / \mathrm{kg} /$ day $)$ azothiop- 

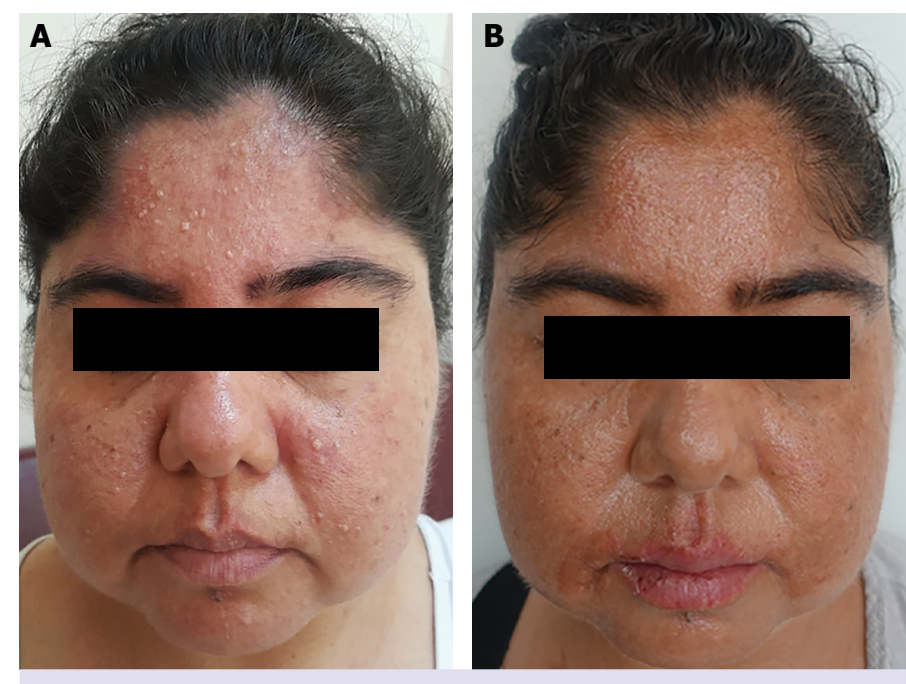

FIGURE 1. (A) A large number of yellow-colored papules on the forehead, cheek, and chin. (B) Hyperproliferation of the sebaceous glands (HEx4).

urine, $6 \mathrm{mg} /$ day methylprednisolone was used. She had been receiving cyclosporine and steroid treatment for 25 years in reduced doses. The lesions, which started in the fifth year of treatment, had gradually increased over the years. Dermatological examination showed that there were a large number of yellow-colored papules on the forehead, cheek, and chin, ranging from 1-4 mm (Fig. 1A). Histopathological examination of the punch biopsy on the forehead of the patient revealed hyperproliferation of the sebaceous glands (Fig. 1B). The patient was diagnosed with sebaceous hyperplasia and systemic isotretinoin treatment was started at $40 \mathrm{mg} /$ day $(0.6 \mathrm{mg} / \mathrm{kg} /$ day $)$. The patient continued cyclosporine treatment at the same dose. After a twomonth treatment, the lesions on the face of the patient showed near-total regression (Fig. 2) The drug dose was then reduced to $20 \mathrm{mg} /$ day $(0.3 \mathrm{mg} / \mathrm{kg} /$ day $)$ and continued for four months. No side effects were seen except mild cheilitis. One year after discontinuation of the therapy, no recurrence was observed. Patient's consent was obtained for this study.

\section{DISCUSSION}

Cyclosporin is used in the treatment of many skin diseases, especially autoimmune diseases, as well as the prevention of tissue rejection in organ transplantation by selective immunosuppressive activity. Ginjival hyperplasia, hypertrichosis, acne, pruritus, keratosis pilaris and Raynaud phenomenon are the main mucocuta-

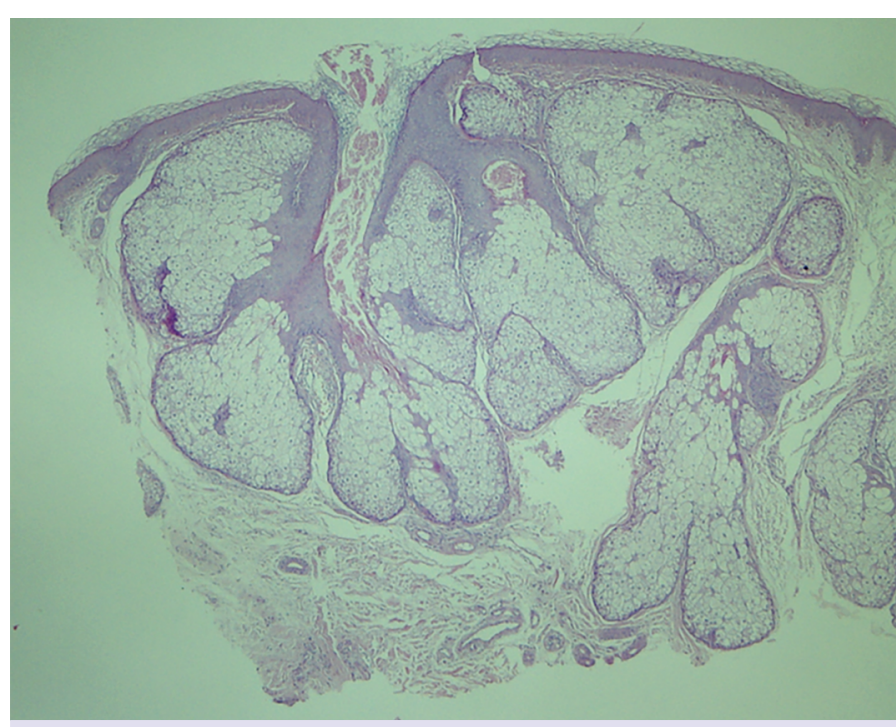

FIGURE 2. Almost complete regression of lesions after two months of treatment.

neous side effects associated with cyclosporine. Acne, keratosis pilaris, sebaceous hyperplasia and epidermoid cysts, which are rare side effects, are frequently seen in renal transplant patients, and it is suggested that the pilosebaceous unit develops as a result of occlusion with keratinous material. It is thought that cyclosporine causes these side effects by increasing the secretion of sebum in 5-alpha reductase enzyme activity. According to another opinion, cyclosporine accumulates in cutaneous tissue due to high lipid solubility and leads to dysplastic epithelial proliferation $[1,3]$.

Regarding the development of sebaceous hyperplasia in renal transplant patients, in two separate studies, $10 \%$ and $8 \%$ were found and all patients received cyclosporine. In the group of renal transplantation patients not receiving cyclosporine, $\mathrm{SH}$ development was not observed [4, 5]. Moreover, other immunosuppressive drugs, such as azathioprine and prednisolone, have not been reported to be associated with $\mathrm{SH}$ [5]. These results suggest that $\mathrm{SH}$ development is directly related to the use of cyclosporine.

In most cases, the minimum time required for $\mathrm{SH}$ development after starting cyclosporine is four years [6]. This suggests that the drug causes lesions with cumulative effects. All cases reported in the literature are male and are not seen in pediatric patients. It has been suggested that the lesions do not develop because sebaceous glands are not fully developed in children [3]. Our case was female was a distinctive feature. 
The treatment methods of cryotherapy, curettage, excision, electrolysis, topical photodynamic therapy and carbon dioxide laser can be used according to the patient's preference and the number of lesions in the treatment of $\mathrm{SH}$, which is located in the facial area and causes cosmetic concerns. Systemic isotretinoin is an effective and easy to treat treatment for patients with multiple lesions, especially when compared to other treatments. Sebostatic and antiproliferative effects are well known. It has been shown to cause apoptosis and pause in the cell cycle [1]. The disadvantage of treatment appears to be a recurrence in a short time. However, this can be avoided by reaching a cumulative dose with low-dose, long-term regimens. Controlled studies are needed for this. We planned a 6 -month maintenance treatment with $20 \mathrm{mg} /$ day $(0.3 \mathrm{mg} / \mathrm{kg} /$ day $)$ after obtaining a complete response with isotretinoin treatment at $40 \mathrm{mg} /$ day $(0.6 \mathrm{mg} / \mathrm{kg} /$ day) for two months in our patient.

\section{RESULTS}

Some of the transplant patients were treated with cyclosporine for many years and cumulatively affected with a large percentage of papules. Systemic isotretinoin therapy is an effective and safe option at low doses in these patients. In addition, all of the cases in the literature were male, and the first female renal transplant patient with $\mathrm{SH}$ induced by cyclosporine use was presented.
Informed Consent: Written informed consent was obtained from the patient for the publication of the case report and the accompanying images.

Conflict of Interest: No conflict of interest was declared by the authors.

Financial Disclosure: The authors declared that this study has received no financial support.

Authorship Contributions: Concept - CC, FTD, ZT; Design - CC, FTD, ZT; Supervision - CC, FTD, EGU; Fundings - CC, EGU, TZ; Materials - CC; Data collection and/or processing - CC; Analysis and/or interpretation - EGU, CC, FTD; Literature review - CC; Writing - CC; Critical review - CC.

\section{REFERENCES}

1. Cortés B, Kaya G. Multiple Eruptive Sebaceous Hyperplasia Secondary to Cyclosporin in a Patient with Bone Marrow Transplantation. Dermatopathology 2016;3:79-82. [CrossRef

2. Jung HY, Kim M, Cho BK, Park HJ. A Case of Cyclosporine-Induced Sebaceous Hyperplasia in a Renal Transplant Patient Successfully Treated with Isotretinoin. Ann Dermatol 2016;28:271-2. [CrossRef]

3. Pang SM, Chau YP. Cyclosporin-induced sebaceous hyperplasia in renal transplant patients. Ann Acad Med Singap 2005;34:391-3.

4. Bencini PL, Montagnino G, Sala F, De Vecchi A, Crosti C, Tarantino A. Cutaneous lesions in 67 cyclosporin-treated renal transplant recipients. Dermatologica 1986;172:24-30. [CrossRef]

5. Lugo-Janer G, Sánchez JL, Santiago-Delpin E. Prevalence and clinical spectrum of skin diseases in kidney transplant recipients. J Am Acad Dermatol 1991;24:410-4. [CrossRef]

6. de Berker DA, Taylor AE, Quinn AG, Simpson NB. Sebaceous hyperplasia in organ transplant recipients: shared aspects of hyperplastic and dysplastic processes? J Am Acad Dermatol 1996;35:696-9. [CrossRef] 